\title{
Resilience and sense of coherence in first year medical students - a cross-sectional study
}

Lena Luibl', Julia Traversari' ${ }^{2}$, Friedrich Paulsen ${ }^{1}$, Michael Scholz ${ }^{1 *+}$ (D) and Pascal Burger ${ }^{3+}$

\begin{abstract}
Background: A broad range of studies show that medical students often have a significantly deteriorated mental health status. Although starting medical school with values comparable to the population average, only a few semesters later, medical undergraduates show increased rates of psychological risk states and some manifest mental illnesses, such as burnout and depression. In our survey we intentionally assessed mental health parameters from a salutogenetic, i.e. resource-oriented point of view.

Methods: We examined first-year medical students in a cross-sectional study and assessed sense of coherence (SOC) and resilience as parameters from the salutogenesis model by Antonovsky in a structured way using validated, self-administered questionnaires. In total, we examined 236 students of human medicine, dentistry and molecular medicine at the Friedrich-Alexander-University Erlangen-Nürnberg (FAU).

Results: Our analyses showed significantly higher values of resilience among male students compared to female students $(p<0.01)$. In contrast, even though a significant correlation between resilience and SOC was observed, only a non-significantly lower value of SOC was found in female students. Compared to the reference sample our medical students in their first year of study showed significantly lower values for resilience $(p<0.01)$ and SOC $(p<0.01)$.

Conclusion: Resilience and SOC are known to correlate with psychological stress (burnout parameters) and depression. In order to keep protective factors like SOC and resilience in medical students at a good and healthy level we see the necessity to address that problem proactively and educationally. Integrating training focused on the preservation of the students' own mental health into the medical curriculum from the beginning of university courses, and throughout the whole medical study course, is essential and should be an obligatory training goal. Based on our study results, we also deem it necessary to think about ways to adapt the measures for the genderspecific needs of our students, e.g. dependent on their biological gender.
\end{abstract}

Keywords: Mental health status, Undergraduate medical students, Salutogenesis, Resilience, Sense of coherence, Medical education

\footnotetext{
* Correspondence: michael.scholz@fau.de

${ }^{+}$Michael Scholz and Pascal Burger contributed equally to this work.

${ }^{1}$ Institute of Functional and Clinical Anatomy, Friedrich-Alexander-University

Erlangen-Nürnberg, Universitätsstr. 19, 91054 Erlangen, Germany

Full list of author information is available at the end of the article
}

\section{$\triangle B M C$}

(C) The Author(s). 2021 Open Access This article is licensed under a Creative Commons Attribution 4.0 International License, which permits use, sharing, adaptation, distribution and reproduction in any medium or format, as long as you give appropriate credit to the original author(s) and the source, provide a link to the Creative Commons licence, and indicate if changes were made. The images or other third party material in this article are included in the article's Creative Commons licence, unless indicated otherwise in a credit line to the material. If material is not included in the article's Creative Commons licence and your intended use is not permitted by statutory regulation or exceeds the permitted use, you will need to obtain permission directly from the copyright holder. To view a copy of this licence, visit http://creativecommons.org/licenses/by/4.0/ The Creative Commons Public Domain Dedication waiver (http://creativecommons.org/publicdomain/zero/1.0/) applies to the data made available in this article, unless otherwise stated in a credit line to the data. 


\section{Background}

Physicians must be able to care for their patients in a holistic way. In other words, not only by treating cases of acute or chronic illness, but also by implementing strategies to prevent mental and physical disorders. However, compared to the general population, physicians themselves show a massively increased prevalence of mental disorders such as depression, anxiety disorders or substance use disorders [1-4]. Many studies [5-7] have successfully demonstrated that undergraduate physicians already show a very high frequency of risk factors for mental health problems [1, 8, 9] such as burnout, and some manifest mental disorders [10-16]. This is particularly noteworthy, as the future physicians seem to begin their studies with increased levels of disorders such as depression and anxiety disorders compared to the general population [1, 17-19].

To our knowledge, no obligatory courses, activities or learning goals to prevent this problem are integrated in the medical curriculum to this day. Nevertheless, over the last years, the awareness on the topic of increased levels of psychological disorders among medical students has risen. Thus, extracurricular programs on the improvement of mental health [20-25] and student interest groups, like the Lachschaft, an initiative by medical students in Erlangen for the promotion of mental health, have been established.

Not only the presence of mental disorders (or potentially already existing damage), but particularly the preconditions and mental health resources that students possess should be assessed and ameliorated. In this study we refer to Aaron Antonovsky's salutogenesis model, which examines the factors that benefit health and focuses on personal resources like resilience and sense of coherence. In this model (Fig. 1) the development of disorders and preservation of mental health depends on the individual perception and assessment of stressors and the reaction to the latter. Resilience represents the individual ability to deal with stressors and integrate them into daily life without persistent psychological damage. As a possible protective mechanism in actively preventing mental disorders, resilience encompasses behaviors and thoughts which can be learned and developed, such offering much curricular promise [26]. Sense of coherence (SOC) describes a global orientation that expresses the extent to which one has a pervasive, enduring though dynamic feeling of confidence. It states that (i) the stimuli that arise from the inner and outer environment throughout life are structured, predictable and explainable, (ii) the individual has the resources to meet the demands these stimuli make, and (iii) these demands are challenges that are worth engaging with and explaining. Thus, the SOC can be interpreted as a mean to measure one's attitude towards life. Antonovsky describes that a person with a strong SOC can perceive the uniqueness of each situation in which he or she is involved and can thus be flexible [27]. The SOC comprises of 3 components, comprehensibility, manageability and meaningfulness. According to Antonovsky, meaningfulness is the most important component and is therefore most strongly represented. Regarding these 3 factors, the possible importance of the SOC for medical training and teaching can be deduced. For achieving the goal to become a medical expert, students need learn to understand, classify and manage situations for their patients' best outcome. The constellation of the SOC's components results in the overall SOC and consequently describes the stability of an individual's psychological constitution. SOC and its components alike are closely linked to external and social resources. The aim of our study was to examine the mental health of medical students using two salutogenic factors, i.e. the parameters of resilience and SOC, which were specifically chosen as we consider them to be of particular importance in a physician's working environment and behavior due to their strong correlation with mental health [27-30].

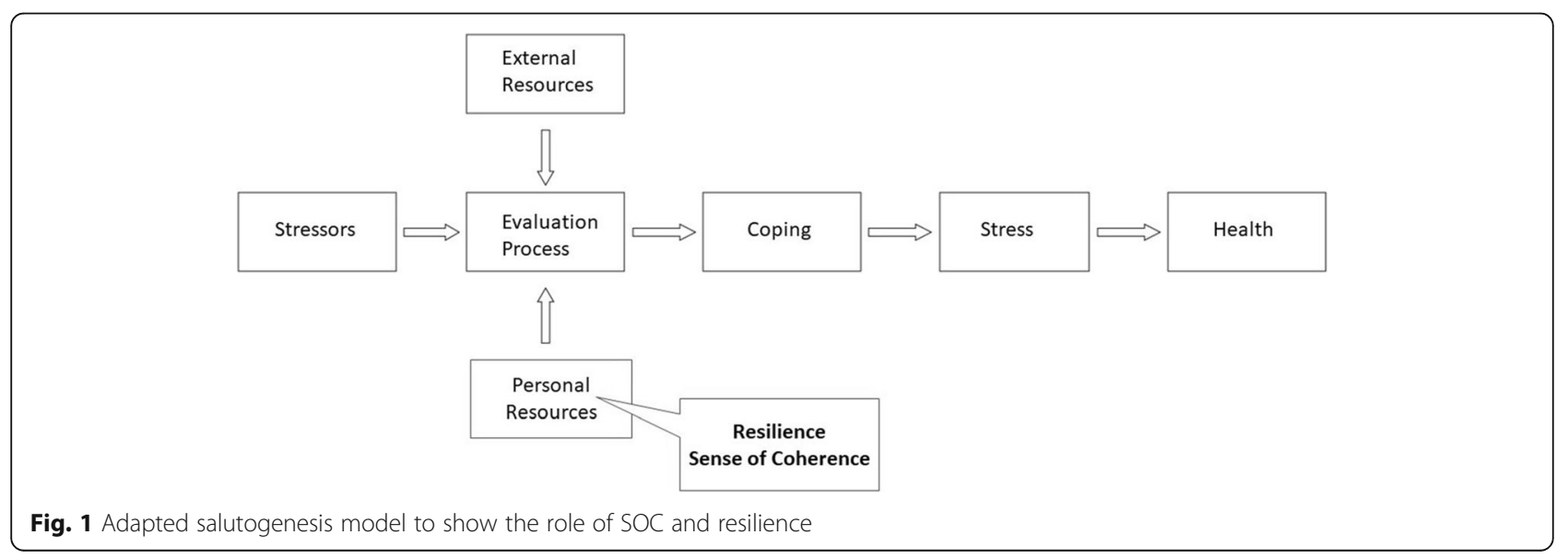


These results could demonstrate a need and the opportunity to study and adapt didactical and interventional approaches for the improvement of mental health in medical students by using these specific parameters. Considering that a majority of medical students is female [31] with constantly rising numbers of women starting to study medicine and regarding the gender-related discrepancy in psychological health issues [32], we were especially interested in whether there is a difference with regard to the salutogenetic factors between genders. This additional dimension could allow the development of more tailored course offers aiming at the prevention of mental health risks and keeping our students functional.

\section{Methods}

We conducted our study surveying first year medical students from all 3 medical study curricula (human medicine, dentistry and molecular medicine) offered in Erlangen.

\section{Measuring instruments}

The RS-13 is a validated, self-administered survey for the measurement of mental resilience $[24,33]$ and is an abridged version of the RS- 25 which covers several subscales: purposeful life, perseverance, equanimity, selfreliance and existential loneliness [23]. In contrast, the RS-13 measures resilience as a one-dimensional global value. By summing up the values, the test persons are divided into "low, moderate and high resilience". A score of up to 66 points is considered to signify low, up to 72 points moderate and 73 points and above high resilience.

The SOC L-9 is the validated short form ("Leipziger Kurzfassung") of the standard survey for measuring SOC. Values for the German general population for the SOC-scale were established in a survey including almost 2000 participants, several short versions, including the SOC-L9, were tested to be valid and reliable for sufficiently estimating the SOC in German participants [34]. The SOC L-9, comprises 9 items, which achieve a high measuring accuracy (Cronbach's Alpha $=0.87)[35,36]$. Particularly, it tests for comprehensibility, manageability and meaningfulness giving these factors different weight. According to Antonovsky, meaningfulness is the most important component and is therefore most strongly represented. The evaluation is carried out by summation, a higher value indicates a stronger expression of the SOC.

Statistical analysis was conducted using the statistical software $R$ [37]. Beside descriptive statistics we performed tests for normal distribution (KolmogorovSmirnoff-test) and tested - as there was a normal distribution - for differences by using t-tests. Furthermore, we conducted a one-way-ANOVA and a chi-square $\left(x^{2}\right)$ test estimation the association of factors with our results and performed a correlation analysis.

This study is a subsegment of the ESTRELLAS surveys on medical students, approved by a positive vote of the Ethics Committee of the Friedrich-Alexander-University Erlangen-Nürnberg (FAU).

\section{Results}

During the winter semester 2017, a total of 236 medical students took part in the survey. There were no dropouts within the groups and all participating students handed in their questionnaires filled out completely. The distribution of the study participants according to the study programs and biological gender can be seen in Table 1. In each of the medical courses of studies, an unequal gender distribution in favor of female students was observed. This was most evident in students of molecular medicine, with more than $80 \%$ female participants.

\section{Resilience}

The descriptive statistics of the resilience values according to RS-13, both overall and in the subgroups, divided by gender, are shown in Table 2. Accordingly, subjects whose aggregated resilience value ranks between 13 and 66 have low, between 67 and 72 moderate and between 73 and 91 high resilience. A test for normal distribution of the original data was negative, but due to the central limit theorem, the test statistic based on $n=236$ follows a t-distribution (asymptotic t-test). Differences in the mean resilience scores between gender groups were analyzed by carrying out a t-test and were considered significant at $p \leq 0.05$ (difference $=3.56, \mathrm{CI}(0.95)=[0.32$; 6.81]). The differences between male and female students were statistically significant in the whole study group $(p<0.01)$. Furthermore, we conducted a chisquare $\left(\chi^{2}\right)$ test to identify associations between gender and those resilience levels. In our group of students, a distinctly greater amount of highly resilient individuals was present in the male student group (statistic $=14.72$; $\mathrm{df}=2 ; p<0.01)($ Fig. 2). The distribution of the resilience levels within the respective student subgroups (human medicine, dental medicine, molecular medicine) is presented in Fig. 3. There were no statistically significant differences detectable between those groups (statistic $=$ 8.51; $\mathrm{df}=4 ; p=0.07$ ). Overall, the mean value for resilience in the general population is 70 points (range: 13$91, \mathrm{SD}=12$ ) [33]. The comparison between our medical students and the reference sample by means of a t-test showed that the medical students have significantly lower average resilience scores (difference $=-2.44$, $\mathrm{CI}(0.95)=[-3.96 ;-0.92] ; p<0.01)$. 
Table 1 Probands from medical courses of studies

\begin{tabular}{lccccc}
\hline Field of study & Gender & Total number & Mean age & Min age & Max age \\
\hline Human medicine & $\mathbf{m}$ & 56 & 21.8 & 18 & 31 \\
& $\mathbf{f}$ & 99 & 20.9 & 18 & 33 \\
\hline Dentistry & $\mathbf{m}$ & 17 & 21.4 & 19 & 27 \\
\hline Molecular medicine & $\mathbf{f}$ & 33 & 22.8 & 20 & 30 \\
& $\mathbf{f}$ & 5 & 20.2 & 19 & 22 \\
\hline
\end{tabular}

Table 2 Values given by test participants for resilience, subdivided according to fields of study and gender. ${ }^{*}=$ significant difference with $p<0.01$.

\begin{tabular}{|c|c|c|c|c|c|}
\hline Field of study & Gender & Total number & Mean & SD & Median \\
\hline \multirow[t]{3}{*}{ All } & & 236 & 67.56 & 12 & 69 \\
\hline & m & 78 & $69.95^{*}$ & 12 & 73 \\
\hline & f & 158 & $66.39 *$ & 12 & 68 \\
\hline \multirow[t]{3}{*}{ Human medicine } & & 155 & 67.68 & 13 & 69 \\
\hline & m & 56 & 69.68 & 13 & 73 \\
\hline & $f$ & 99 & 66.56 & 12 & 68 \\
\hline \multirow[t]{3}{*}{ Dentistry } & & 50 & 68.00 & 12 & 70 \\
\hline & m & 17 & 73.47 & 9 & 76 \\
\hline & $f$ & 33 & 65.18 & 13 & 69 \\
\hline \multirow[t]{3}{*}{ Molecular medicine } & & 31 & 66.26 & 7 & 66 \\
\hline & m & 5 & 61.00 & 8 & 64 \\
\hline & $f$ & 26 & 67.27 & 6 & 67 \\
\hline
\end{tabular}




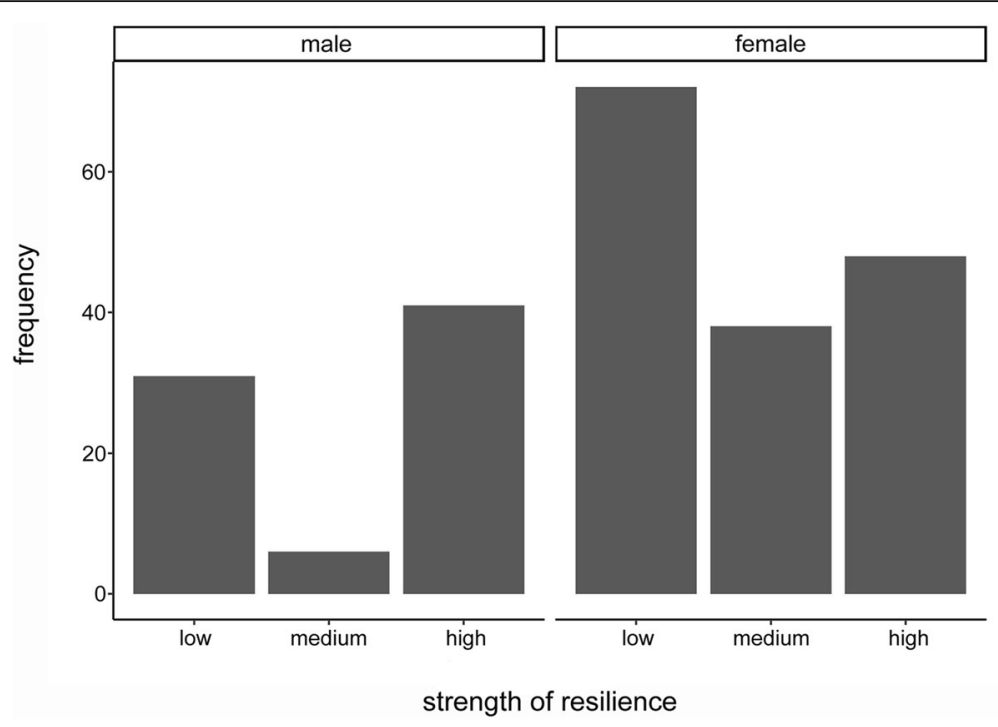

Fig. 2 Frequency of resilience expressions according to RS-13 in the gender groups

\section{Sense of coherence}

Table 3 presents total number, mean, median and SD of the SOC-L9 scores, overall and in subgroups, broken down by gender. In order to test for differences in the mean of SOC, an asymptotic t-test was performed. A slightly higher mean SOC value for male participants compared to female participants (see Fig. 4) was observed. However, in contrast to resilience, there was no statistically significant difference (difference $=0.87$, $\mathrm{CI}(0.95)=[-0.56 ; 2.30] ; \quad p=0.23)$ detectable between male and female subjects. The analysis of our subgroups within the study program (human medicine, dental medicine, molecular medicine) can be seen in Fig. 5. To test for differences in the mean of the groups, we conducted an anova-test based on a regression of the SOC L-9 values on study program dummies. Here as well there was no statistically significant difference in the absolute SOC L-9 values $(p=0.66)$. Concerning the SOC, our first-year medical students also had significantly lower values compared to the reference sample (mean value for $\operatorname{men}=50.68, \mathrm{SD}= \pm 7.77$; mean value for women $=49.68, \mathrm{SD}= \pm 7.78[38])$. The results of a t-test comparing all medical students to the reference sample both overall and categorized by gender - indicate that our group of medical students showed a significantly lower mean value of SOC (medical students: overall:

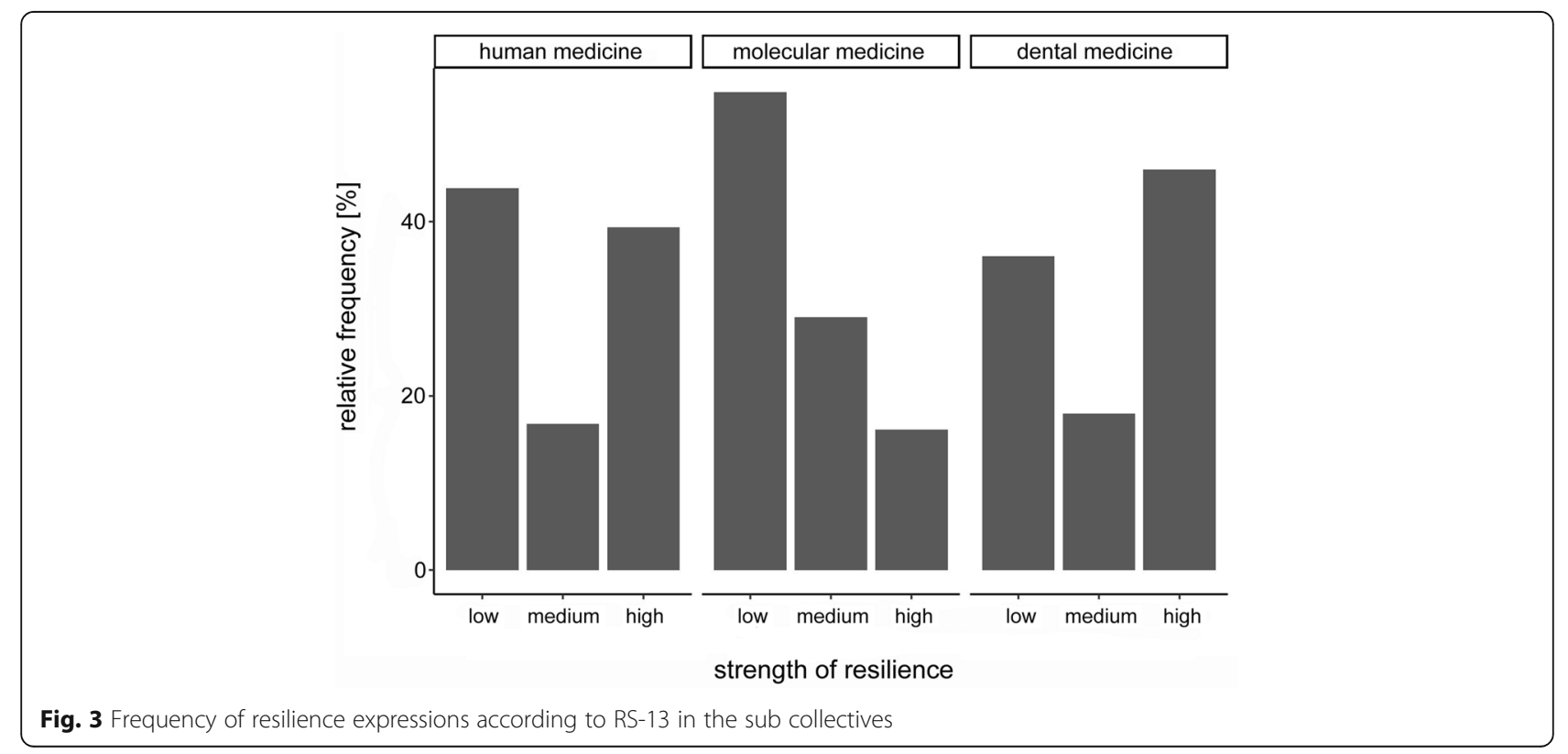


Table 3 The values given by the participants for SOC, subdivided according to fields of study and gender.

\begin{tabular}{|c|c|c|c|c|c|}
\hline Field of study & Gender & Total number & Mean & SD & Median \\
\hline \multirow[t]{3}{*}{ All } & & 233 & 42.57 & 5.06 & 43 \\
\hline & m & 76 & 43.16 & 5.27 & 44 \\
\hline & $f$ & 157 & 42.29 & 4.95 & 42 \\
\hline \multirow[t]{3}{*}{ Human medicine } & & 152 & 42.53 & 5.34 & 43 \\
\hline & m & 54 & 43.13 & 5.38 & 44 \\
\hline & $f$ & 98 & 42.20 & 5.31 & 42 \\
\hline \multirow[t]{3}{*}{ Dentistry } & & 50 & 43.04 & 4.58 & 42 \\
\hline & m & 17 & 43.88 & 4.04 & 44 \\
\hline & $f$ & 33 & 42.61 & 4.84 & 42 \\
\hline \multirow[t]{3}{*}{ Molecular medicine } & & 31 & 42.00 & 4.43 & 43 \\
\hline & m & 5 & 41.00 & 7.91 & 41 \\
\hline & $f$ & 26 & 42.19 & 3.66 & 43 \\
\hline
\end{tabular}

mean $=42.57 ; \mathrm{CI}(0.95)=[41.92 ; 43.22], \quad p<0.01 ;$ male medical students: mean $=43.16 ; \mathrm{CI}(0.95)=[41.95 ; 44.36]$, $p<0.01$; female medical students: mean $=42.29$; $\mathrm{CI}(0.95)=[41.51 ; 43.07], p<0.01)$.

\section{Relationship between resilience and SOC}

Based on the construct of salutogenesis presented in Fig. 1 , a connection between the resilience and the SOC seems to be a logical consequence. We performed a correlation analysis between the two parameters (Fig. 6) which revealed a moderate correlation $\left(R^{2}=0.43\right)$ between resilience and SOC in the whole study cohort $(N=236)$. In addition, there were no statistically significant differences in the relationship between resilience and SOC with respect to gender.

\section{Discussion}

The results of our studies are in line with recent literature on mental health problems of medical students and physicians [7, 39-43]. In contrast to most studies on medical students which focus on symptoms such as suicidal tendencies or disorders like depression, we examined our collective of future physicians for parameters of mental health using a salutogenetic approach. The factors examined, SOC $[27,28]$ and resilience $[29,30]$, are strongly correlated with symptoms of mental disorders such as depression and anxiety disorders. Our data indicate an impairment of those protective factors for mental health after a little more than the first semester of study. We found a large proportion in our group of medical students at that stage who had low to moderate resilience values and distinctly reduced SOC in comparison to the population average. As previously shown in other studies, this circumstance correlates to an increased vulnerability to mental illnesses. This could in turn account for the increased prevalence of mental disorders over the course of medical studies [18, 44, 45]. Due to the character of the parameters we chose, our results also suggest that this development is probably caused by an insufficient adaptation to psychological 


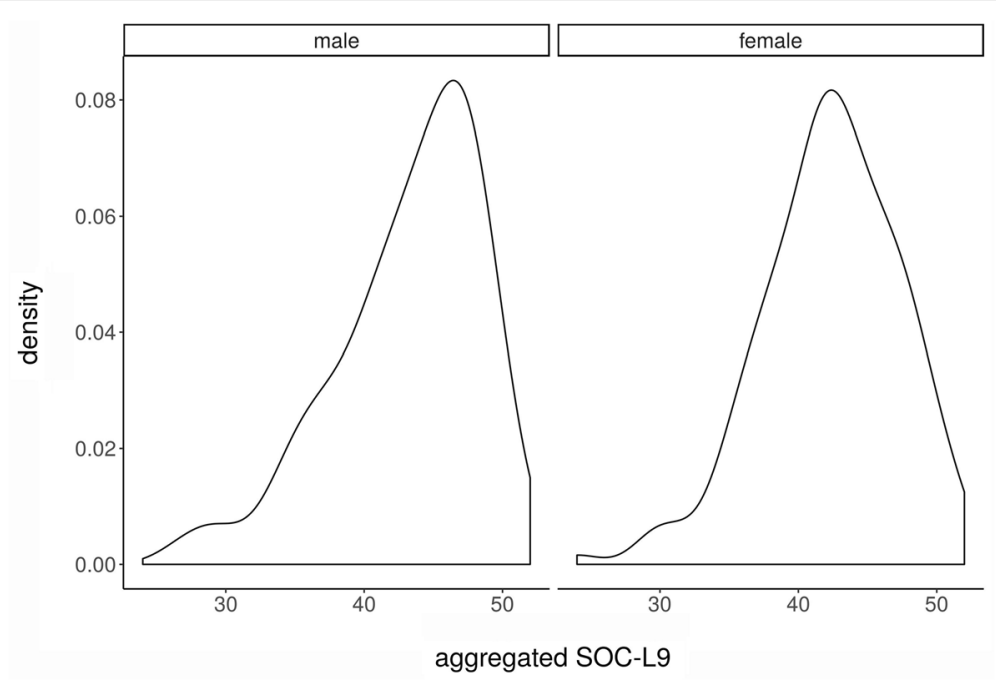

Fig. 4 Kernel density estimates of SOC L9 values in the gender groups

stress and a lack of coping mechanisms. In an earlier study, we already found lower SOC values in female students $[18,46]$, and our recent data indicates that the factor resilience follows an even more gender-imbalanced pattern. Although our survey was administered to a relatively small-sized sample group, we were able to find a significant difference between the gender groups with regards to their resilience. Thus, female students not only appear to be at higher risk for psychiatric disorders $[47,48]$ but also disproportionally lack protective features [32]. This is very relevant for medical students and future physicians for several reasons, since almost two thirds $(64.2 \%$ in the winter semester $2019 / 2020)$ of medical students in Germany are female [49]. A similar trend towards a female majority in the student body can be seen in the US, as reported in 2017 by the Association of American Medical Colleges [31, 42]. Extrapolating our results, we conclude that the majority of medical students find themselves at risk with regards to their relative lack of psychologically protective factors. Physicians have an increased suicide rate compared to all other professions, including the paradoxical finding of female physicians having much higher suicide rates than their male equivalents [50]. We therefore consider gender-specific prevention courses to be all the more important.

Based on our analysis, we conclude that SOC and resilience have a mutual impact on each other. The connection between the two parameters has already been discussed in some studies $[51,52]$. This circumstance in turn can possibly influence the development of mental disorders: In case of successful coping with a crisis, the awareness of the problem rises through a higher comprehensibility. A better manageability is perceived and retrospectively a value is recognized in the experienced event, which allows a crisis to be considered meaningful.
The more often an individual experience occurs regaining the original state of mind after a crisis - and the more understandable the situation gets, the more psychologically stable the individual gets. Therefore, it seems plausible that a stronger $\mathrm{SOC}$ is connected to a higher resilience - up to a certain extent both factors might be influenced and changed.

Back in 2008, Emma Warnecke wrote: "[...] students are taught about managing the health of others, there is an imperative to provide them with effective, evidencebased ways to manage their own stress." [53]. We consider it mandatory for medical education and our future physicians to learn evidence-based ways to compensate for their own stress and keep their own mental health intact in a structured manner. Consequently, and in accordance with our approach, medical curricula should be didactically and content-wise orientated towards creating opportunities that allow the participants to grow in line with their challenges. We believe it far more likely for medical students to remain mentally healthy if the course program included resilience-skills as a central learning goal and was adapted to gender-specific needs $[2,18]$. Established programmes to improve resilience already exist. For example, "The Road to Resilience" was developed by the American Psychological Association (APA) and "10 ways to build resilience" offers concrete instructions for learning and implementing resilient behaviour $[26,54]$. These or similar programs could be adapted for medical students and be integrated as obligatory content at medical schools.

From our own experience and projects at other faculties [23, 25, 55-58], we consider relaxation and mindbody techniques to be feasible and promising options. A firm curricular anchoring of teaching and training these techniques could be achieved by implementing recurring 


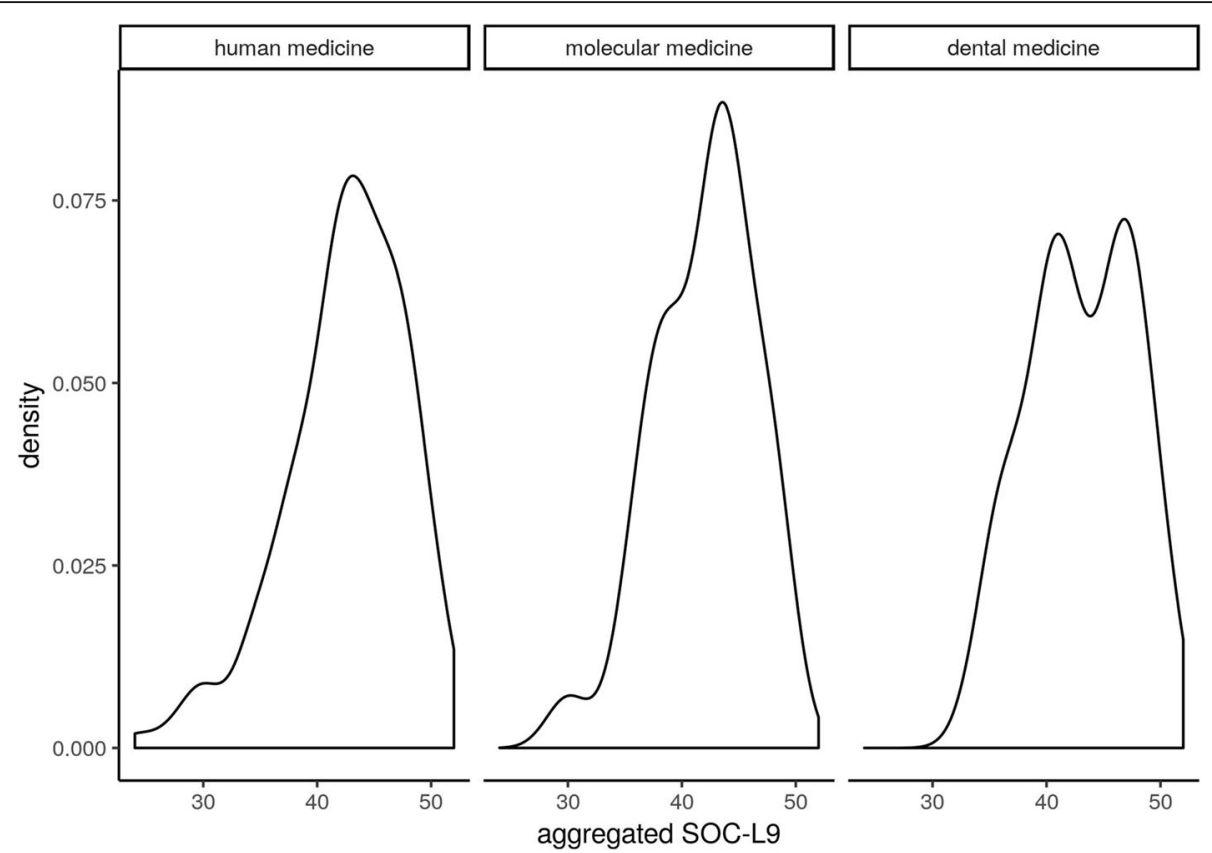

Fig. 5 Core density estimates of SOC L9 values in the subcollectives

and ultimately self-applied exercises in the curriculum. These measures might result in a higher sensitivity for the future physicians own stress tolerance and the habit of self-administered mental health maintenance $[1,18$, 59]. Moreover, to reinforce mental stability, we would recommend e.g. applying the construct of resilience on the didactic blueprint of teaching units. The concept of learning in the context of manageable critical situations could be applied to more than just to emergency medicine, where it is already partly being done. There, for example, training is carried out in a team on a simulation patient. Even if mistakes are being made, in the end the patient survives, the student gets a comprehensible and constructive feedback and repeats the training as long as it is necessary in order to be able to handle the situation sufficiently. With this approach the student has experienced manageability and comprehensibility of the scenario despite an extremely stressful situation $[22,60$, 61], dosing the feeling of loss of control and frustration to a manageable level. We recommend to anchor stress management and promotion of resilience as crucial learning objectives in medical education.

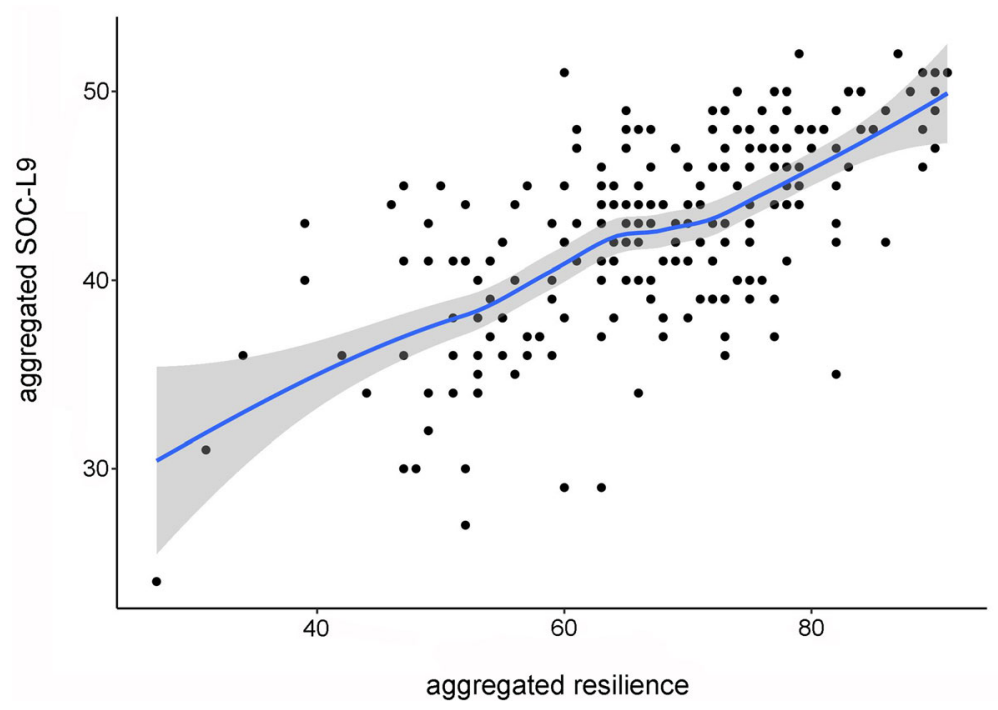

Fig. 6 Relationship between resilience and SOC values 


\section{Conclusions}

The medical curriculum is known to be a source of severe psychological stress for students and medical students' average mental health parameters deteriorate significantly over the course of studies. Resilience and SOC make a considerable contribution to the maintenance of mental health and can be seen as resources for university and postgraduate period alike. We therefore consider it essential to integrate preventive courses for mental health and also apply structures that promote salutogenesis in the curriculum to strengthen resistance to mental disorders in medical students. The maintenance of one's own mental health should be defined as a central learning goal in the curriculum and the courses to achieve it should adapt measures to biological gender.

\section{Abbreviation}

SOC: Sense of coherence

\section{Acknowledgements}

This publication is part of the first author's dissertation. The present work was performed in (partial) fulfilment of the requirements for obtaining the degree "Dr. med." of LL. We are thankful to Simonetta Batteiger for her help with the english manuscript. Furthermore, we thank Christoph Rust for his assistance with the statistical data analysis.

\section{Authors' contributions}

MS, PB and LL did study conceptualization and design, MS coordinated and executed the data collection, PB and LL did the literature research. LL performed the data transfer, qualitative coding and statistical analysis, JT supervised statistics. LL drafted the manuscript, all authors read, refined and approved the final manuscript.

\section{Funding}

Open Access funding enabled and organized by Projekt DEAL.

\section{Availability of data and materials}

The datasets used and analysed in the current study are part of the secured data base of the medical education research unit at the Institute of Functional and Clinical Anatomy.

\section{Ethics approval and consent to participate}

The study was approved by the local ethics committee of the FriedrichAlexander-University Erlangen-Nürnberg (ESTRELLAS). All participants gave their written consent to their participation, the pseudonymized data processing and publication.

\section{Consent for publication}

Not applicable.

\section{Competing interests}

All authors have no competing interests.

\section{Author details}

${ }^{1}$ Institute of Functional and Clinical Anatomy, Friedrich-Alexander-University Erlangen-Nürnberg, Universitätsstr. 19, 91054 Erlangen, Germany. ${ }^{2}$ Institute of Anatomy, University of Zurich, Winterthurerstrasse 190, 8057 Zürich, Switzerland. ${ }^{3}$ Department of Psychiatry, Psychiatric University Hospital, Lenggstrasse 31, 8008 Zurich, Switzerland.

Received: 3 August 2020 Accepted: 19 February 2021

Published online: 04 March 2021

\section{References}

1. Scholz M, Neumann C, Steinmann C, Hammer CM, Schröder A, Eßel N, et al. Entwicklung und Zusammenhang von Arbeitsverhalten, BurnoutBeschwerden und Lebensqualität bei Studierenden der Humanmedizin vom
Studienstart bis zum ersten Staatsexamen. PPmP-Psychotherapie. Psychosomatik. Medizinische Psychologie. 2015;65(03/04):93-8.

2. Scholz M, Burger P, Paulsen F. Auswahl von Medizinstudierenden: Sollen, können und aushalten. Dtsch Arztebl International. 2018;115(41):A-1799.

3. Mayer FB, Santos IS, Silveira PS, Lopes MHI, de Souza ARND, Campos EP, et al. Factors associated to depression and anxiety in medical students: a multicenter study. BMC medical education. 2016;16(1):282.

4. Dyrbye LN, Thomas MR, Shanafelt TD, editors. Medical student distress: causes, consequences, and proposed solutions. Mayo Clinic Proceedings; 2005: Elsevier.

5. Pacheco JP, Giacomin HT, Tam WW, Ribeiro TB, Arab C, Bezerra IM, et al. Mental health problems among medical students in Brazil: a systematic review and meta-analysis. Brazilian Journal of Psychiatry. 2017;39(4):369-78.

6. Erschens R, Keifenheim KE, Herrmann-Werner A, Loda T, Schwille-Kiuntke J, Bugaj TJ, et al. Professional burnout among medical students: systematic literature review and meta-analysis. 2018.

7. IsHak W, Nikravesh R, Lederer S, Perry R, Ogunyemi D, Bernstein C. Burnout in medical students: a systematic review. Clin Teach. 2013;10(4):242-5.

8. Dyrbye $L$, Shanafelt T. A narrative review on burnout experienced by medical students and residents. Med Educ. 2016;50(1):132-49.

9. Dyrbye LN, Thomas MR, Huntington JL, Lawson KL, Novotny PJ, Sloan JA, et al. Personal life events and medical student burnout: a multicenter study. Acad Med. 2006;81(4):374-84.

10. Rotenstein LS, Ramos MA, Torre M, Segal JB, Peluso MJ, Guille C, et al. Prevalence of depression, depressive symptoms, and suicidal ideation among medical students: a systematic review and meta-analysis. Jama. 2016:316(21):2214-36.

11. Brooks E, Gendel MH, Early SR, Gundersen DC. When doctors struggle: current stressors and evaluation recommendations for physicians contemplating suicide. Archives of suicide research. 2018;22(4):519-28.

12. Slavin SJ, Schindler DL, Chibnall JT. Medical student mental health 3.0: improving student wellness through curricular changes. Academic Medicine. 2014;89(4):573

13. Jeong Y, Kim JY, Ryu JS, Eun Lee K, Ha EH, Park H. The associations between social support, health-related behaviors, socioeconomic status and depression in medical students. Epidemiology and health. 2010;32.

14. Dyrbye LN, Harper W, Durning SJ, Moutier C, Thomas MR, Massie FS Jr, et al. Patterns of distress in US medical students. Medical teacher. 2011:33(10):834-9.

15. Sarokhani D, Delpisheh A, Veisani Y, Sarokhani MT, Manesh RE, Sayehmiri K. Prevalence of depression among university students: a systematic review and meta-analysis study. Depress Res Treat. 2013;2013.

16. Voltmer E, Kötter T, Spahn C. Perceived medical school stress and the development of behavior and experience patterns in German medical students. Medical teacher. 2012:34(10):840-7.

17. Hope $V$, Henderson M. Medical student depression, anxiety and distress outside N orth a merica: a systematic review. Med Educ. 2014;48(10):963-79.

18. Burger PH, Tektas OY, Paulsen F, Scholz M. Vom Studienstart bis zum ersten Staatsexamen-Zunahme von Depressivität bei gleichzeitigem Verlust des Kohärenzgefühls und der psychischen Lebensqualität in höheren Semestern Humanmedizin. PPmP-Psychotherapie. Psychosomatik. Medizinische Psychologie. 2014;68(08):322-7.

19. Puthran R, Zhang MW, Tam WW, Ho RC. Prevalence of depression amongst medical students: a meta-analysis. Med Educ. 2016;50(4):456-68.

20. Gordon JS. Mind-body skills groups for medical students: reducing stress, enhancing commitment, and promoting patient-centered care. BMC Med Educ. 2014;14:198

21. Saunders PA, Tractenberg RE, Chaterji R, Amri H, Harazduk N, Gordon JS, et al. Promoting self-awareness and reflection through an experiential mind-body skills course for first year medical students. Med Teach. 2007; 29(8):778-84.

22. Scholz M, Neumann C, Wild K, Garreis F, Hammer CM, Ropohl A, et al, Teaching to relax: development of a program to potentiate stress-results of a feasibility study with medical undergraduate students. Appl Psychophysiol Biofeedback. 2016:41(3):275-81.

23. Wild K, Scholz M, Ropohl A, Brauer L, Paulsen F, Burger PH. Strategies against burnout and anxiety in medical education--implementation and evaluation of a new course on relaxation techniques (Relacs) for medical students. PLoS One. 2014;9(12):e114967.

24. Holtzworth-Munroe A, Munroe MS, Smith RE. Effects of a stressmanagement training program on first- and second-year medical students. J Med Educ. 1985;60(5):417-9. 
25. Kuhlmann SM, Burger A, Esser G, Hammerle F. A mindfulness-based stress prevention training for medical students (MediMind): study protocol for a randomized controlled trial. Trials. 2015;16(1):40.

26. Newman R. APA's resilience initiative. Prof Psychol Res Pract. 2005;36(3):227.

27. Antonovsky A. The structure and properties of the sense of coherence scale. Soc Sci Med. 1993;36(6):725-33.

28. Antonovsky A. The life cycle, mental health and the sense of coherence. Isr J Psychiatry Relat Sci. 1985.

29. Noeker M, Petermann F. Resilienz: Funktionale Adaptation an widrige Umgebungsbedingungen. Z Psychiatr Psychol Psychother. 2008;56(4):255-63.

30. Pechmann C, Petermann F, Brähler E, Decker O, Schmidt S. Führt niedrige Resilienz zu einer stärkeren psychischen Belastung? Psychiatr Prax. 2015; 42(04):197-201.

31. AoAMC. More Women Than Men Enrolled in US Medical Schools in 2017 https://www.aamc.org/news-insights/press-releases/more-women-menenrolled-us-medical-schools-2017: AAMC News. AAMC Press Washington, DC; 2017 [Available from: https://www.aamc.org/news-insights/press-relea ses/more-women-men-enrolled-us-medical-schools-2017.

32. Burger $P$, Scholz M. Gender as an underestimated factor in mental health of medical students. Annals of Anatomy-Anatomischer Anzeiger. 2018;218:1-6.

33. Leppert K, Koch B, Brähler E, Strauß B. Die Resilienzskala (RS)-Überprüfung der Langform RS-25 und einer Kurzform RS-13. Klinische Diagnostik und Evaluation. 2008:1(2):226-43.

34. Singer S, Brähler E. Die "Sense of Coherence Scale" Testhandbuch zur deutschen Version: Vandenhoeck \& Ruprecht GmbH \& Co KG Göttingen; 2007.

35. Schumacher J, Gunzelmann T, Brähler E. Deutsche Normierung der sense of coherence scale von Antonovsky. Diagnostica. 2000;46(4):208-13.

36. Schumacher J, Wilz G, Gunzelmann T, Brähler E. The Antonovsky sense of coherence scale. Test statistical evaluation of a representative population sample and construction of a brief scale. Psychother Psychosom Med Psychol. 2000;50(12):472-82.

37. R Core Team. A Language and Environment for Statistical Computing. 3.6.2 ed. Vienna: R Foundation for Statistical Computing; 2019.

38. Hannöver W, Michael A, Meyer C, Rumpf H-J, Hapke U, John U. Die Sense of coherence Scale von Antonovsky und das Vorliegen einer psychiatrischen Diagnose. PPmP-Psychotherapie. Psychosomatik. Medizinische Psychologie. 2004:54(03/04):179-86.

39. lorga M, Dondas C, Zugun-Eloae C. Depressed as Freshmen, Stressed as Seniors: The Relationship between Depression, Perceived Stress and Academic Results among Medical Students. Behav Sci (Basel). 2018;8:8.

40. Jurkat HB, Richter L, Cramer M, Vetter A, Bedau S, Leweke F, et al. Depression and stress management in medical students. A comparative study between freshman and advanced medical students. Nervenarzt. 2011; 82(5):646-52.

41. Kohls N, Bussing A, Sauer S, Riess J, Ulrich C, Vetter A, et al. Psychological distress in medical students - a comparison of the universities of Munich and Witten/Herdecke. Z Psychosom Med Psychother. 2012;58(4):409-16.

42. Arigoni F, Bovier PA, Sappino AP. Trend of burnout among Swiss doctors. Swiss Med Wkly. 2010;140:w13070.

43. Eckleberry-Hunt J, Lick D. Physician depression and suicide: a shared responsibility. Teach Learn Med. 2015;27(3):341-5.

44. Leppert K, Richter F, Strauß B. Wie resilient ist die Resilienz? PiDPsychotherapie im Dialog. 2013;14(01):52-5.

45. Kröninger-Jungaberle $H$, Grevenstein D. Development of salutogenetic factors in mental health-Antonovsky's sense of coherence and Bandura's self-efficacy related to Derogatis' symptom check list (SCL-90-R). Health Qual Life Outcomes. 2013;11(1):80.

46. Scholz M, Neumann C, Ropohl A, Paulsen F, Burger PH. Risk factors for mental disorders develop early in German students of dentistry. Ann Anat. 2016;208:204-7.

47. Ernst C. Geschlechtsunterschiede bei psychischen Erkrankungen. Die bessere und die schlechtere Hälfte? Geschlechtsunterschiede in der Prävalenz psychischer Krankheiten aus epidemiologischer Sicht. Psychische Erkrankungen bei Frauen Karger, Basel. 2001:47-61.

48. Müters S, Hoebel J, Lange C. Diagnose Depression: Unterschiede bei Frauen und Männern; 2013.

49. Bildung und Kultur; Studierende an Hochschulen. Fachserie 11: Statistisches Bundesamt; erschienen am 18.10.2019, korrigiert am 01.11.2019.
50. Reimer C, Trinkaus S, Jurkat HB. Suizidalität bei Ärztinnen und Ärzten. Psychiatr Prax. 2005;32(08):381-5.

51. Schumacher J, Leppert K, Gunzelmann T, Strauß B, Brähler E. Die resilienzskala-ein fragebogen zur erfassung der psychischen widerstandsfähigkeit als personmerkmal. Z Klin Psychol Psychiatr Psychother. 2005;53(1):16-39.

52. Leppert K, Gunzelmann T, Schumacher J, Strauss B, Brähler E. Resilience as a protective personality characteristic in the elderly. Psychother Psychosom Med Psychol. 2005;55(8):365-9.

53. Warnecke E, Quinn S, Ogden K, Towle N, Nelson MR. A randomised controlled trial of the effects of mindfulness practice on medical student stress levels. Med Educ. 2011;45(4):381-8.

54. APA. The Road To Resilience: APA; [Available from: https://studentsuccess. unc.edu/files/2015/08/The-Road-to-Resiliency.pdf.

55. Mache S, Vitzthum K, Groneberg D, Klapp BF. How to stay mentally healthy during medical education. Stress coping and relaxation behaviour of female and male students. Med Teach. 2012;34(10):867.

56. Schroeder DG. The effects of group study skills counseling and applied relaxation on study behaviors and test anxiety in medical and dental students. Annual Conference on Research in Medical Education Conference on Research in Medical Education. 1980;19:175-80.

57. Dobkin PL, Hutchinson TA. Teaching mindfulness in medical school: where are we now and where are we going? Med Educ. 2013:47(8):768-79

58. Rosenzweig S, Reibel DK, Greeson JM, Brainard GC, Hojat M. Mindfulnessbased stress reduction lowers psychological distress in medical students. Teach Learn Med. 2003;15(2):88-92.

59. Ritter JC. Stressbelastung bei Medizinstudierenden: Ist das Erlernen einer Entspannungstechnik während des.

60. Mühlinghaus I, Scheffer S, Antolic A, Gadau J, Ortwein H. Teamarbeit und Fehlermanagement als Inhalte des Medizinstudiums. GMS Z Med Ausbild. 2007:24(4):2007-24.

61. Mueller M, Heller AR, Koch T. A new simulator-based psychological training on crisis management. Medical education. 2005:39(11):1155.

\section{Publisher's Note}

Springer Nature remains neutral with regard to jurisdictional claims in published maps and institutional affiliations.
Ready to submit your research? Choose BMC and benefit from:

- fast, convenient online submission

- thorough peer review by experienced researchers in your field

- rapid publication on acceptance

- support for research data, including large and complex data types

- gold Open Access which fosters wider collaboration and increased citations

- maximum visibility for your research: over $100 \mathrm{M}$ website views per year

At $\mathrm{BMC}$, research is always in progress.

Learn more biomedcentral.com/submissions 